The Social Sciences 14 (10): 356-360, 2019

ISSN: $1818-5800$

(C) Medwell Journals, 2019

\title{
Application of Unmanned Aerial Vehicle Data to Land form Pothole
}

\author{
Nattaporn Yuang Ngoen, Rapeeporn Samart and Anuwat Kochawan \\ Department of Geography and Geoinformation, Faculty of Humanities and Social Sciences, \\ Phranakhon Rajabhat University, Bangkok, Thailand
}

\begin{abstract}
This research was an applying data from unmanned aerial vehicle of landform pothole studying in Sam Phan Bok, Pho Sai district, Ubon Ratchathani province. The objective of the research was to compare data of landform from unmanned aerial vehicle and fieldwork and the data of landform pothole were width, length, depth, density, pattern and distribution. The study was conducted by using the photo from unmanned aerial vehicle to define study points then measuring size of sample and compare with data from field working width and length and it found that the deviation from both measuring was not over than $2.5 \%$. The result of both measuring was accuracy and reliable around $97.5 \%$ but for the depth of hole was not able to use data from unmanned aerial vehicle because pothole had water logged and water plants. The distribution of the area in $100 \mathrm{~m}^{2}$ found that the average of pothole was appear around 9 . The pattern and density found that majority patterns were single and close to each other and the second were small potholes that appear in big pothole and usually found distribution in study area.
\end{abstract}

Key words: Unmanned aerial vehicle, geomorphology, landform, pothole, distribution, average

\section{INTRODUCTION}

Geomorphology is a study about the Earth, natural form, formation procedure, development, as well as current transformation (RIT., 2006, 2001). In geomorphology, 5 elements are often used in studying as followings. Landform consists of form, size, topology, surface, height from the sea level, landform type and slope. The structure of sediment or stone layer which are parts of the landform and the controlling factors of the evolution, topology and landform usually reflects such structure. The action process occurring to the landform can explain the formation of the landform. Landform elements including both the part which has decayed into soil and the hard rock part. The same type of material when being in different environments may have different endurance. The length of time in forming and destroying the landform defines the real age of the area or compares the age of connecting landform (Eiamnor, 2006).

Sam Phan Bok is stone rapids or potholes which are under Mekhong river, Pho Sai district, Ubonratchathani province. It happens from vortex force eroding the area into plenty of pools and holes appearing to be seen during the dry season when the water is gone and appearing above water like a mountain in the middle of Mekhong river around October-May which is called "Mekhong
Grand Canyon" by local people. After that, flood water will come over those holes covering them under the river or so called "Sam Phan Bok" following the fact that there are over 3,000 big and small holes under the rapids ("Bok" in Laos language means "pool"). Geomorphologic characteristics are stone rapids. Mostly are sandstones, conglomerate sandstones, and nodule stones of Phu Phan formation (DNR., 2007) which have been eroded by Mekhong river for million years until the area became naturally and unusually beautiful. Due to these naturally outstanding characteristics, this area is allocated as part of Pha Chan Sam Phan Bok Geographical National Park, welcoming a lot of both Thai and Foreign tourists. However, since, the community is still lacking geomorphological information of area formation, the researcher became interested in studying the geomorphological characteristics of the area, so as to gather knowledge about a natural tourist destination and to find reference information for the local community to use in advising and educating the tourist.

In conducting geom orphological research, field study is usually combined. Sometimes, data gained from geo-information technology, especially, remote sensing system is used to support the study because some areas cannot be accessed (GISTDA., 2009). In Thailand, there is a satellite for natural resources exploration called Thai

Corresponding Author: Nattaporn Yuang Ngoen, Department of Geography and Geoinformation,

Faculty of Humanities and Social Sciences, Phranakhon Rajabhat University,

Bangkok, Thailand 


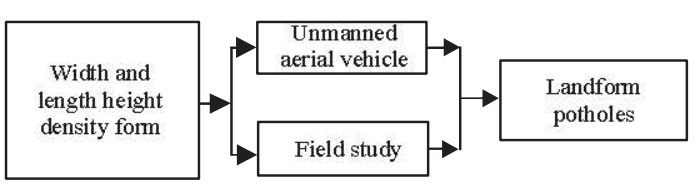

Fig. 1: Conceptual framework

Chot which can record panchromatic pictures with high resolution. Aerial photos can be found from Royal Thai Survey Department. However, both satellite data and aerial photos have some limitations. A specially expertized technician is required in recording photos and the budget is quite high. Besides, currently available photos cannot display area data to be up-to-date and meet with the user's demand. As some areas cannot be accessed, geomorphological study using unmanned aerial vehicle is an option which is important and useful towards the research. It is an application of a small unmanned aerial vehicle using radio frequency in remote controlling to take photos instead of using a real airplane. It is cheaper, more convenient and faster to use an unmanned aerial vehicle. Therefore, it can save a lot of time and cost in doing a research. Data gained by using an unmanned aerial vehicle is another option in doing geomorphological study which is time and cost saving.

Objective: To compare data gained from an unmanned aerial vehicle and field data in studying landform of potholes in Sam Phan Bok area, Pho Sai district, Ubonratchathani province.

Conceptual framework: This research has an objective to compare data gained from an unmanned aerial vehicle and field data in studying landform of potholes under the following conceptual framework (Fig. 1).

\section{MATERIALS AND METHODS}

This research has an objective to compare studying methods of pothole landform between field study and unmanned aerial vehicle which consists of landform: width, length, depth, height, density, form and distribution. The researching method is as written below:

Study landform data from field study and collect data about the position data of pothole by global positioning system within the area of Sam Phan Bok.

Enter position data by using ArcGIS program covered with $10 \times 10 \mathrm{~m}$ grid and using simple random method to identify 20 samples of pothole landform.

Use data from unmanned aerial vehicle taken on 19th January, 2019 with $6 \mathrm{~cm}$ resolution by ArcGIS and measure the size of pothole by using measure function. Use data from field study and unmanned aerial vehicle in comparing the deviation (Suphet, 2008).

Researching results: By studying the landform of potholes including width, length, depth, height, density, form and distribution by comparing landform data gained from field study and unmanned aerial vehicle, the followings were found.

The size of potholes include width measured from the narrowest side to the opposite side. The length is measured from the long side to the opposite side. The depth of the pothole is measured from the deepest point of the hole. The results are as shown in Table 1.

Based on the table, it is found that deviation between field study and unmanned aerial vehicle of 20 samples is not much as the deviation is not over $2.5 \%$. When comparing to the measurement done in the field, the result has high accuracy and reliability. However, the depth cannot be viewed from an unmanned aerial vehicle because there is water logged and water plants inside the pothole, making it impossible to take a photo of the pothole bottom. Field data is therefore, necessary to be used in studying. After considering, it is found that the width, length and depth of the pothole is highest at the top part. This is because in the high-tide season, floodwater will come on top with higher speed of water current than that of the bottom. Therefore, it has higher force in bringing sediment to erode the top surface faster than the bottom side which makes the top part of the pothole bigger than the bottom (Sengupta and Kale, 2011) and causes erosion in the plain level as well as static deterioration by the weather when appearing above the water.

The measuring of density of pothole by unmanned aerial vehicle was done by using grid index command with $100 \mathrm{~m}^{2}$ (Fig. 2) in ArcGIS program. By randomly sampling and counting the holes, it was found that within $100 \mathrm{~m}^{2}$, there are 9 holes in average. The density of potholes in Sam Phan Bok area is usually high on top level. Since, the element of most stones is silicon with less alumina, the stone level is durable against erosion by water current in Mekhong river. For this reason, the landform of potholes is denser with more complete condition than the bottom. Moreover, at the bottom, the period of flooding time by water from Mekhong river is longer than the top level. Consequently, the bottom part is eroded and destroyed by water current, causing less potholes to be found. When the water level in Mekhong river is higher that it covers Sam Phan Bok, the top water current is stronger than the bottom where there is less 
The Soc. Sci., 14 (10): 356-360, 2019

Table 1: Comparison of the width, length, depth of the pothole from field study and unmanned aerial vehicle

\begin{tabular}{|c|c|c|c|c|c|c|}
\hline \multicolumn{3}{|l|}{ Width (cm) } & \multicolumn{4}{|l|}{ Length $(\mathrm{cm})$} \\
\hline Unmanned aerial vehicle & Field & Deviation & Unmanned aerial vehicle & Field & Deviation & Depth \\
\hline 92 & 92 & - & 149 & 150 & 1 & 107 \\
\hline 85 & 86 & -1 & 184 & 180 & +4 & 65 \\
\hline 153 & 152 & +1 & 132 & 130 & +3 & 106 \\
\hline 156 & 159 & -3 & 206 & 201 & +5 & 111 \\
\hline 74 & 74 & - & 84 & 87 & -3 & 45 \\
\hline 84 & 83 & +1 & 1107 & 110 & -3 & 50 \\
\hline 61 & 61 & - & 51 & 50 & +1 & 48 \\
\hline 62 & 60 & +2 & 65 & 64 & +1 & 35 \\
\hline 109 & 109 & - & 141 & 144 & -3 & 101 \\
\hline 179 & 179 & - & 231 & 231 & - & 198 \\
\hline 208 & 209 & -1 & 232 & 233 & -1 & 124 \\
\hline 123 & 123 & - & 198 & 198 & - & 173 \\
\hline 144 & 142 & +2 & 152 & 149 & +3 & 88 \\
\hline 86 & 85 & +1 & 112 & 110 & +2 & 60 \\
\hline 69 & 70 & -1 & 85 & 85 & - & 37 \\
\hline 117 & 116 & +1 & 158 & 157 & +1 & 98 \\
\hline 163 & 159 & +4 & 142 & 144 & -2 & 96 \\
\hline 95 & 94 & +1 & 178 & 179 & -1 & 81 \\
\hline 73 & 72 & +1 & 96 & 95 & +1 & 78 \\
\hline 145 & 45 & - & 220 & 217 & +3 & 75 \\
\hline
\end{tabular}

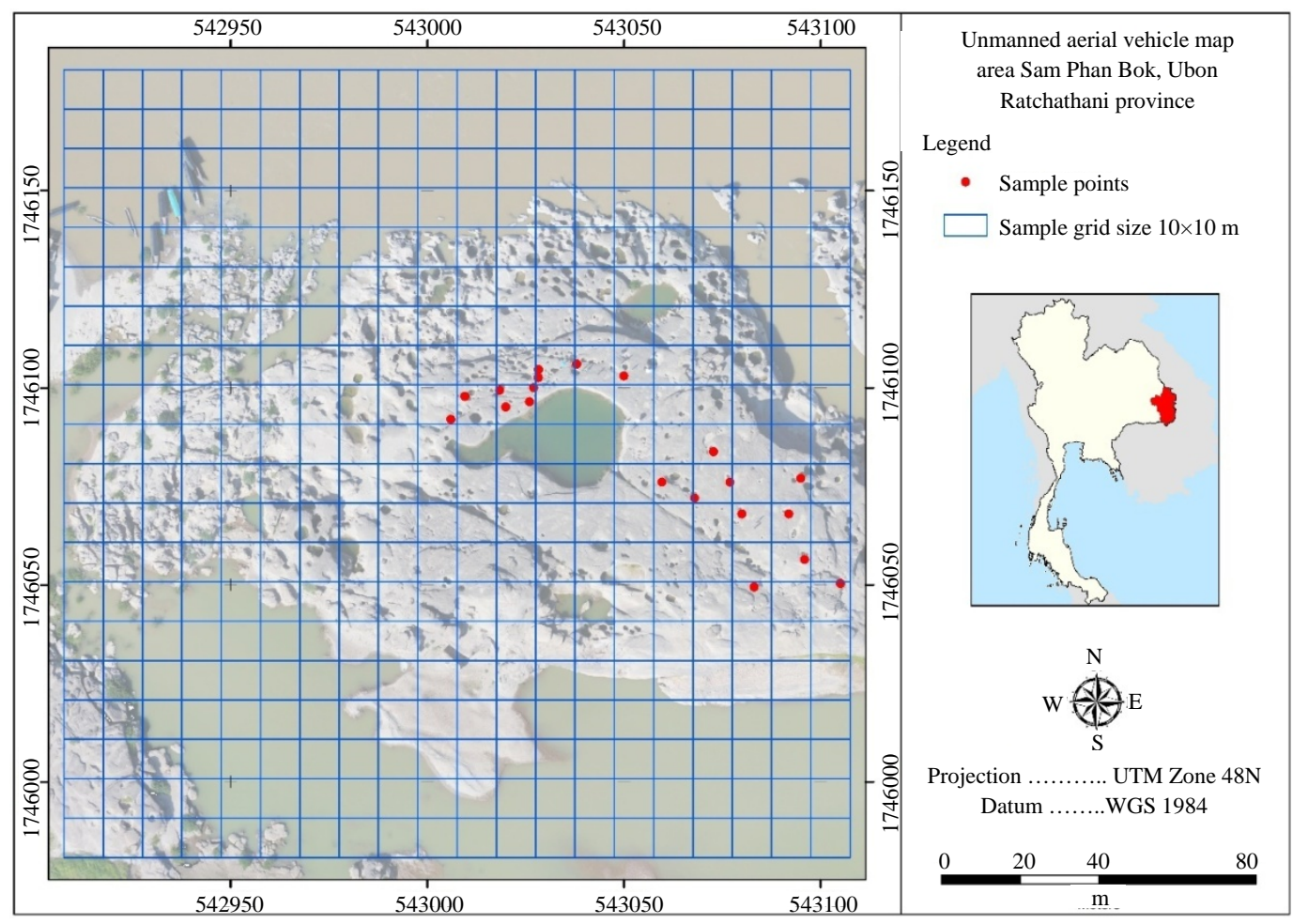

Fig. 2: Studying area and sample random size density and distribution of pothole

tension of the underwater. The top part is eroded by water current, leaving more landform of potholes. Grab and Svensen (2011). Also, the top area is above water level for a longer period of time than the bottom part, so, the stones are deteriorated on spot by weather and flooding water from the rain. From the form and distribution of potholes recorded by unmanned aerial vehicle, the pothole form in Sam Phan Bok area is mostly single form and near to each other. Next is small potholes inside a big one, single potholes and connected potholes with thorough wall. The form of most potholes is single one which is nearby each other (Fig. 3-5). 
(a)

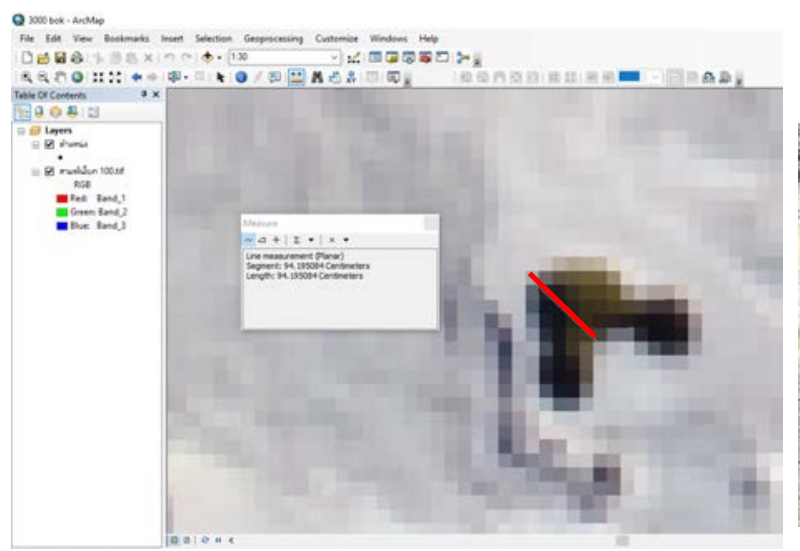

(b)

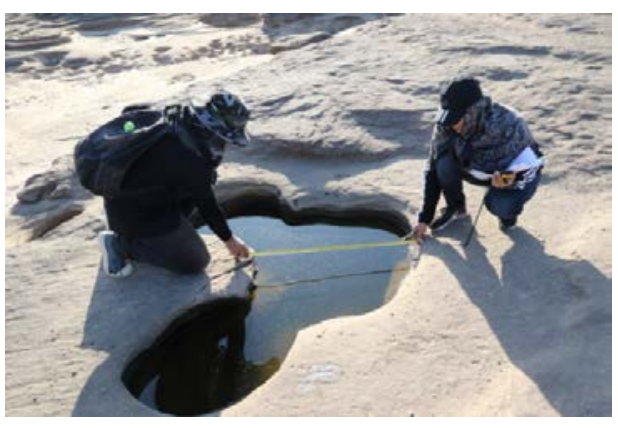

Fig. 3: (a) Measuring the width of the pothole from an unmanned aerial vehicle by ArcGIS program and (b) Measuring the width of the pothole by field study

(a)

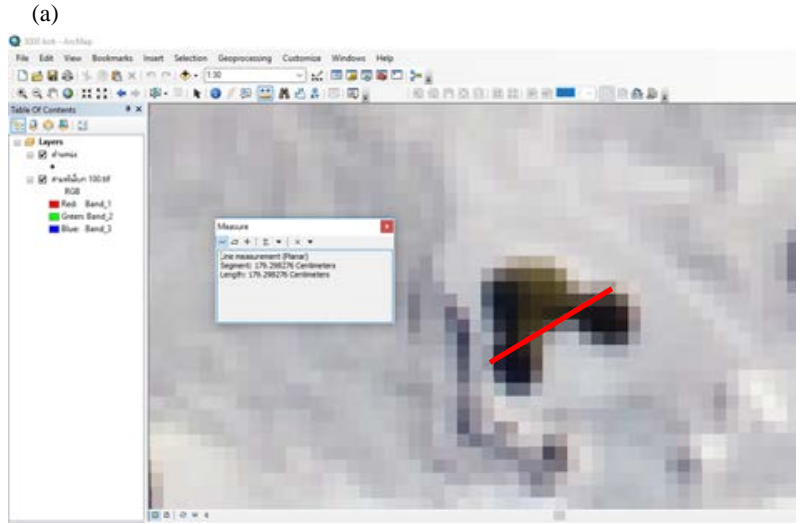

(b)

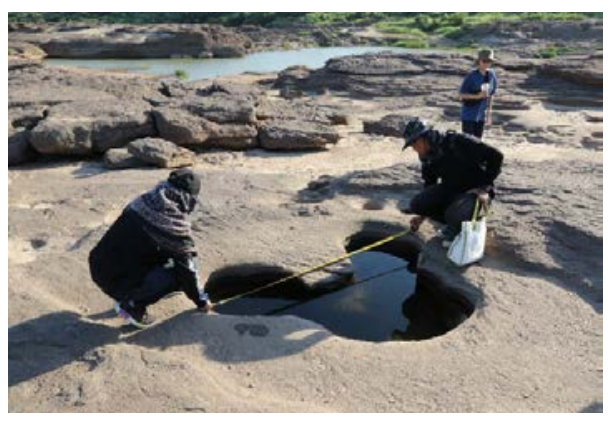

Fig. 4: (a) Measuring the length of the pothole from an unmanned aerial vehicle by ArcGIS program and (b) Measuring the length of the pothole by field study

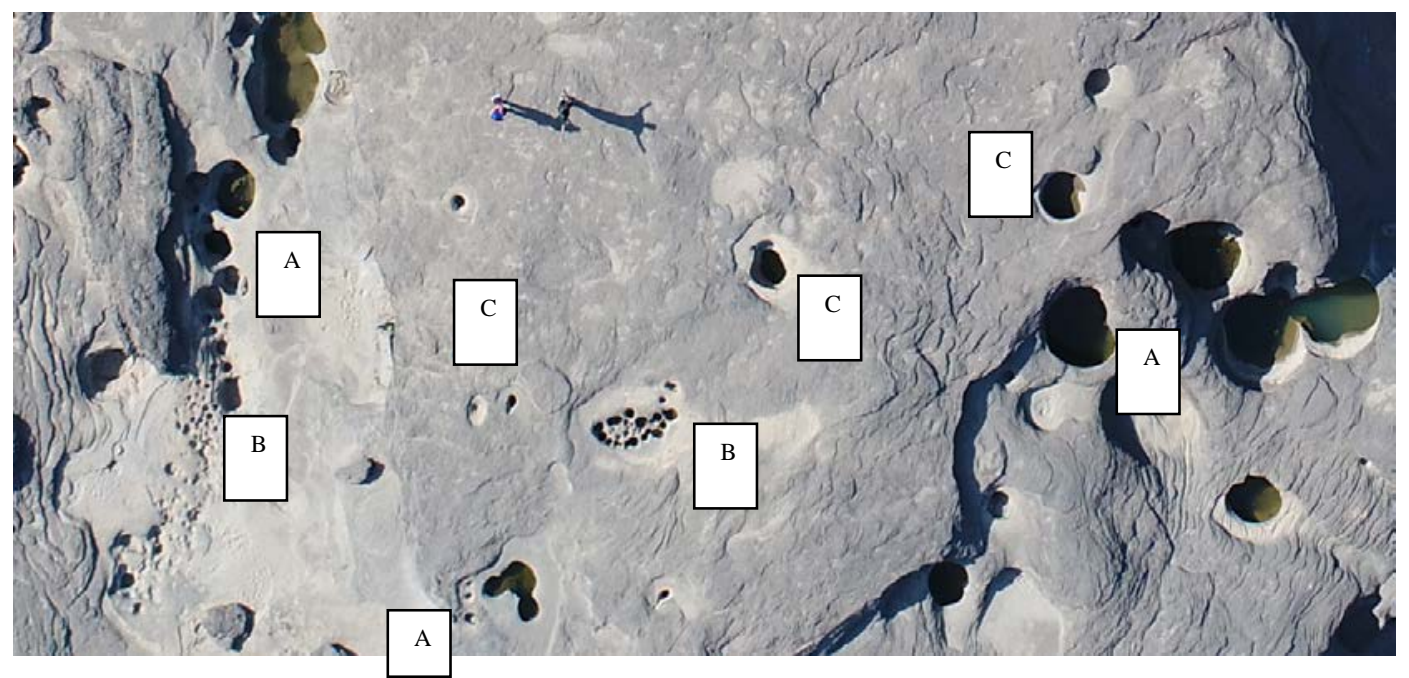

Fig. 5: A picture taken by unmanned aerial vehicle showing A; Single pothole near each other, B; A group of small potholes inside a big one and C; Single potholes spread all over the top of Sam Phan Bok area 


\section{RESULTS AND DISCUSSION}

By the application of unmanned aerial vehicle in studying landform pothole, it was found that the size of potholes in terms of width and length has deviation between data gained from field study and unmanned aerial vehicle of not over $2.5 \%$, while the length cannot be measured by unmanned aerial vehicle because there is water remained in the hole from flooding by Mekhong river and water plants blocking up the bottom of the hole. However, the density, form and distribution of potholes can be measured by unmanned aerial vehicle which found that within $100 \mathrm{~m}^{2}$ area, there are 9 holes in average. Regarding the form and distribution, it was found that most of them are in single form and near to each other. Next is small potholes inside a big one, single potholes and connected potholes with thorough wall which are found scattered on the studied area. When the water tide is high in Mekhong river, it will flood over the potholes. The speed of water current on top is highest because there is tension underwater which slows down the speed of water. Therefore where there is a breaking line or at the part which is durable against erosion, the stones there will remain, making the area higher than other parts. This will cause water current to flow faster and spin. When the water current becomes faster, raising the ability in bringing along sediments in different sizes such as stones, conglomerate, rough sand and fine sand. These sediments will work as a tool in punching the area where there is spinning water, then leave stone breaking lines and erosion both in vertical and horizontal directions which develop into potholes in single form next to each other (Springer et al., 2006). When the water level in Mekhon river is lowered, the sediments inside the hole will silt and remain inside the hole. As a result, sediments in different sizes such as stones, conglomerate, rough sand, fine sand clay and dew are found in the pothole (Fig. 5).

\section{CONCLUSION}

However, in studying geomorphology, field study is always required but some areas cannot be accessed. Using unmanned aerial vehicle is therefore, more time and cost saving than using an airplane or data from a satellite. It can repeatedly take photos in the same area conveniently and quickly, also suitable with studying in a small area.

\section{SUGGESTIONS}

Data collection in Sam Phan Bok area can be done any time. However, sometimes there is waterlogged condition so planning is needed in collecting data to meet the time limit. Also, in regards to the depth, in a waterlogged area with water plants, the camera of unmanned aerial vehicle cannot record through to the ground. In this case, sensor adjustment or another type of recording equipment is required. For example, an infrared camera or more radar should be used or technique in adjusting data from unmanned aerial vehicle by deleting water plants, etc. Moreover, data base of geographical technology system of potholes should be created for studying the erosion rate of the area further.

\section{REFERENCES}

DNR., 2007. Thai geology. Department of Natural Resources, Ministry of Natural Resources and Environment, Bangkok, Thailand.

Eiamnor, A., 2006. Geomorphology. Thai Wattana panich, Bangkok, Thailand.

GISTDA., 2009. Geo-Informatics and Space Technology Textbook. Amarin Printing and Publishing, Thailand,

Grab, S. and H. Svensen, 2011. Rock doughnut and pothole structures of the clarens Fm; Sandstone in the Karoo Basin, South Africa: Possible links to lower Jurassic fluid seepage. Geomorphology, 131: 14-27.

RIT., 2001. Royal Institute of Thailand Geology Dictionary. Aroonkarnpim Publisher, Bangkok, Thailand,

RIT., 2006. Royal Institute of Thailand Geolgraphy Dictionary. 4thEdn., Chuanpim Publisher, Bangkok, Thailand,.

Sengupta, S. and V.S. Kale, 2011. Evaluation of the role of rock properties in the development of potholes: A case study of the Indrayani knickpoint, Maharashtra. 120 157: 165-10.1007/s12040-011-0005-5.

Springer, G.S., S. Tooth and E.E. Wohl, 2006. Theoretical modeling of stream potholes based upon empirical observations from the Orange River, Republic of South Africa. Geomorphology, 82: 160-176.

Suphet, J., 2008. Learn geographic information by ArcGIS Desktop 10.1 S.R. Mass Printing \& Forms Inc., North Reading, Massachusetts. 